\title{
$11 \beta$-Hydroxysteroid Dehydrogenase Type 1 Activity in Short Small-For-GA Children and in Response to GH Therapy
}

\author{
NEHAMA ZUCKERMAN-LEVIN, LARISA TSIVLIN, CARLOS KNOPF, OSHRAT FLOR, ZILA SHEN-ORR, MOSHE LEVIN, \\ AND ZE'EV HOCHBERG
}

Pediatric Endocrinology [N.Z.-L., L.T., O.F., M.L., Z.H.], Meyer Children's Hospital, Haifa 31096, Israel; Metabolic Laboratory [C.K., O.F.], Endocrine Laboratory [Z.S.-O.], Rambam Medical Center, Haifa 31096, Israel; Rappaport Faculty of Medicine and Research Institute [Z.H.], Technion-Israel Institute of Technology, Haifa 31096, Israel

\begin{abstract}
Small for GA (SGA) children are at risk for developing the metabolic syndrome. Those who do not catch up, and remain short (SSGA), may benefit from GH therapy. $11 \beta$ Hydroxysteroid dehydrogenase type $1(11 \beta$-HSD-1) is expressed in visceral fat and is implicated in metabolic morbidity. We hypothesized that SSGA children will have increased basal and glucocorticoid (GC)stimulated $11 \beta$-HSD-1 activity. Twenty SSGA children, aged $7.1 \pm$ $1 \mathrm{y}$ (mean $\pm \mathrm{SD}$ ), were studied before and while on GH therapy and compared with 12 normal age-matched controls. $11 \beta$-HSD-1 activity was evaluated by gas chromatography mass spectrometry (GCMS) of urinary steroid product/substrate ratios. GC-stimulated $11 \beta$-HSD-1 activity was assessed after overnight dexamethazone (DEX), by oral cortisone conversion to cortisol. In SSGA children, $11 \beta$-HSD-1 activity was lower $(p<0.05)$ and GC-stimulated activity enhanced. SSGA children had maximal cortisol generation of $883 \pm 108$ compared with $690 \pm 63 \mathrm{nmol} / \mathrm{L}$ in controls $(p<0.04)$. GH treatment suppressed $11 \beta$-HSD- 1 activity. GC-stimulated enzyme activity correlated negatively with GA $(r=-0.53, p<0.01)$ and birth weight $(r=-0.55, p<0.01)$. SSGA is associated with enhanced GC-stimulated $11 \beta$-HSD-1 activity. This may be programmed in utero, as it is not a function of body composition or secondary metabolic derangement. GH therapy normalizes GCstimulated 11 $\beta$-HSD-1 activity. (Pediatr Res 70: 208-212, 2011)
\end{abstract}

$\mathrm{B}^{\mathrm{s}}$ definition, 5-10\% of all neonates are born small for GA (SGA). Some of these children do not catch up $(1,2)$ and remain short. They may benefit from GH therapy (3-5). This subgroup is designated in this article as short SGA (SSGA). Regardless of their later growth pattern, SGA children are at risk for developing the metabolic syndrome later in life (610). This increased risk for future morbidity has been documented more in SGA individuals who had catch up growth (11-13), than in those who did not (14-16).

Fetal programming might be coupled with several endocrine pathways (17), including the hypothalamic-pituitaryadrenal (HPA) axis (18-20). Indeed, elevated cortisol levels have been reported for adults born SGA (21) and in SSGA children (22-24). Elevated cortisol levels may also be involved in pre- and postnatal growth, as demonstrated by the inverse correlation between cortisol levels in cord blood and embryo length gained during the first trimester in intrauterine growth retarded (IUGR) children (25).

Received November 5, 2010; accepted February 24, 2011

Correspondence: Nehama Zuckerman-Levin, M.D., Pediatric Endocrinology, Meyer Children's Hospital, POB 9602, Haifa 31096, Israel; e-mail: zuckerln@ netvision.net.il
Prereceptor modulation of cortisol by $11 \beta$-hydroxysteroid dehydrogenase type 1 (11 $\beta$-HSD-1) converts cortisone to cortisol for intracrine action (26). Among other regulatory mechanisms of enzyme activity (27), GH inhibits $11 \beta$-HSD-1 activity and gene expression, while GH deficiency is associated with enhanced enzyme activity (28-31).

The working hypotheses of this study were that SSGA children will have increased basal and GC-stimulated $11 \beta$ HSD-1 activity and that these will be inhibited by GH treatment. Toward these hypotheses, we studied in vivo $11 \beta$ HSD-1 activity, as measured by the ratios of urinary cortisol/ cortisone metabolites and cortisone-generated cortisol, and their response to GC in prepubertal SSGA children at baseline and while on human $\mathrm{GH}(\mathrm{hGH})$ therapy.

\section{PATIENTS AND METHODS}

Patients. Between November 2004 and May 2005, 32 prepubertal nonobese children enrolled in this study: 20 SSGA and 12 normal controls, who were appropriate for GA (AGA) siblings of the SSGA group. For SSGA children, pretreatment height was shorter by -2.5 Standard Deviation Score (SDS), and birth weight or length smaller by -2 SDS for GA. SSGA children did not receive glucocorticoids (GCs) during the perinatal period; they were healthy, with no anomalies or perinatal morbidity and had normal GH response to provocative stimulation. Inclusion criteria for controls were good health, prepubertal, normal birth weight, and normal current weight and height for age (Table 1). The Helsinki Committee of the Rambam Medical Center approved the protocol. Parents of all participants signed informed consent after receiving explanations of the study.

Design. Fasting second morning urine samples were collected on d 1 for steroid analysis by gas chromatography mass spectrometry (GCMS) (32). At $2300 \mathrm{~h}$ of $\mathrm{d} 1$, subjects received $1 \mathrm{mg} / \mathrm{m}^{2}$ dexamethazone(DEX) to suppress endogenous cortisol production and to evaluate the effect of GC on $11 \beta$ HSD-1 activity. The next morning, a clinical test of in vivo cortisol generation from cortisone (33) was performed to evaluate $11 \beta$-HSD- 1 activity under the influence of a GC. At $0800 \mathrm{~h}$ the following day, serum cortisol was measured and subjects received enterally $25 \mathrm{mg} / \mathrm{m}^{2}$ cortisone acetate (Rekah, Israel) as a substrate for $11 \beta$-HSD- 1 . The enzymatic product cortisol was measured after 2 and $4 \mathrm{~h}$. Cortisol generation was defined as the increased level over the DEX-suppressed baseline. SSGA children repeated the urine analysis and the GC-stimulated cortisol generation test after $3 \mathrm{mo}$ of GH treatment (Norditropin Simplexx, Novonordisk, Denmark; $0.03 \mathrm{mg} / \mathrm{kg} / \mathrm{d}$ ).

Medical surveillance at baseline and after 3 mo of hGH treatment included auxology; IGF-1 levels; complete blood count; electrolytes; fasting plasma

\footnotetext{
Abbreviations: a-C/b-C, $\alpha$ cortol $/ \beta$ cortol; $\mathbf{a}-\mathbf{C L} / \mathbf{b}-\mathbf{C L}, \alpha$ cortolone $/ \beta$ cortolone; allo THF, $5 \alpha$ tetrahydrocortisol; DEX, dexamethazone; GC, glucocorticoids; GCMS, gas chromatography mass spectrometry; hGH, human GH; 11 $\beta$-HSD-1, 11-beta hydroxysteroid dehydrogenase type 1; SDS, Standard Deviation Score; SGA, small for GA; SSGA, short small for GA; THE, tetrahydrocortisone; THF, tetrahydrocortisol
} 
Table 1. Anthropometric data of SSGA and control subjects

\begin{tabular}{lcc}
\hline & SSGA & Controls \\
\hline$n$ & 20 & 12 \\
Sex (female/male) & $9 / 11$ & $4 / 8$ \\
GA (wk) & $37.2 \pm 2.5$ & $40.3 \pm 2.1$ \\
Age range (y) & $5-9$ & $4.6-11$ \\
Age average (y) & $7.1 \pm 1$ & $8.2 \pm 1.9$ \\
Birth weight (g) & $2070 \pm 390^{*}$ & $3250 \pm 340$ \\
Birth weight (SDS) & $-2.46 \pm 1.1^{*}$ & $-0.4 \pm 0.1$ \\
Current height (cm) & $107.5 \pm 6.5^{*}$ & $125.9 \pm 13.2$ \\
Current height (SDS) & $-2.86 \pm 0.45^{*}$ & $-0.4 \pm 0.7$ \\
Current weight (kg) & $17.2 \pm 3.1^{*}$ & $26.5 \pm 8.4$ \\
BMI (SDS) & $-0.8 \pm 0.7^{*}$ & $-0.1 \pm 1.2$ \\
\hline
\end{tabular}

Mean \pm SD

$* p<0.0001$.

glucose; serum insulin and lipid levels; and a safety panel of liver, renal, and thyroid functions.

Methods. GCMS was performed to evaluate urinary metabolites of cortisol and cortisone as previously described, using gas chromatography equipped with an Agilent 7683 Autoinjector interfaced to an Agilent 5972 massselective detector (32).

$11 \beta$-HSD-1 activity was calculated by the ratios (THF + allo THF)/THE and (THF + allo THF $+\mathrm{a}-\mathrm{C}+\mathrm{b}-\mathrm{C}) /(\mathrm{THE}+\mathrm{a}-\mathrm{CL}+\mathrm{b}-\mathrm{CL})$ where THF denotes tetrahydrocortisol; allo THF, $5 \alpha$ tetrahydrocortisol; THE, tetrahydrocortisone; a-C, $\alpha$ cortol; b-C, $\beta$ cortol; a-CL, $\alpha$ cortolone; and b-CL, $\beta$ cortolone.

$11 \beta$-HSD-2 activity was calculated by the ratios THE/(THF + allo THF and $(\mathrm{a}-\mathrm{CL}+\mathrm{b}-\mathrm{CL}) /(\mathrm{a}-\mathrm{C}+\mathrm{b}-\mathrm{C}) .5 \alpha$ reductase activity was calculated by An/Et, 11-OH-An/11-OH-Et, allo THB/THB, and allo THF/THF where An denotes androsterone; Et, etiocholanalone; 11-OH-An, 11-hydroxyandrosterone; 11-OH-Et, 11-hydroxy etiocholanalone; and allo THB, $5 \alpha$ tetrahydrocorticosterone) $(34,35)$.

Cortisol generation test is based on:

$$
\text { Cortisone- }{ }^{11 \beta-H S D-1} \longrightarrow \text { Total cortisol }
$$

$11 \beta$-HSD-1-generated cortisol $=$ Total cortisol $[-]$ DEX-suppressedcortisol

Serum cortisol was assayed on Immulite 2000 systems (Siemens, Los Angeles, CA, USA). Interassay CV\% 5.2\%-7.4\% and Intrassay CV\% 6.2\%$9.4 \%$.

Statistical analysis. A separate variance $t$ test was performed to validate differences between SSGA and control children. After verification of normal distribution by D'Agostino's K-squared test $(p=0.04)$, paired $t$ test was performed to estimate the impact of $\mathrm{GH}$ treatment. Correlations were calculated to assess interrelation between variables.

Sample size was determined by the number of available patients to this protocol.

Appropriate statistical techniques and methodic caution were used to ensure statistical significant results in this sample size.

\section{RESULTS}

Patients' surveillance, including complete blood count; electrolytes; fasting plasma glucose; serum insulin and lipid levels; and a safety panel of liver, renal, and thyroid functions, and IGF-1 levels, was normal in all subjects.

The mean basal $11 \beta$-HSD-1 activity, calculated from urinary $(\mathrm{THF}+$ allo THF)/THE and (THF + allo THF $+\mathrm{a}-\mathrm{C}+\mathrm{b}-$ $\mathrm{C}) /(\mathrm{THE}+\mathrm{a}-\mathrm{CL}+\mathrm{b}-\mathrm{CL})$ ratios, was lower in the SSGA group $(0.69 \pm 0.24$ and $0.53 \pm 0.16$, respectively, mean $\pm \mathrm{SD})$ than in the control group $(1.00 \pm 0.53, p=0.034$ and $0.71 \pm 0.31$, $p=0.044$, respectively, Fig. 1).

Mean basal urinary $11 \beta$-HSD-2 and $5 \alpha$ reductase activities were comparable in the two groups and on hGH therapy (Table 2).

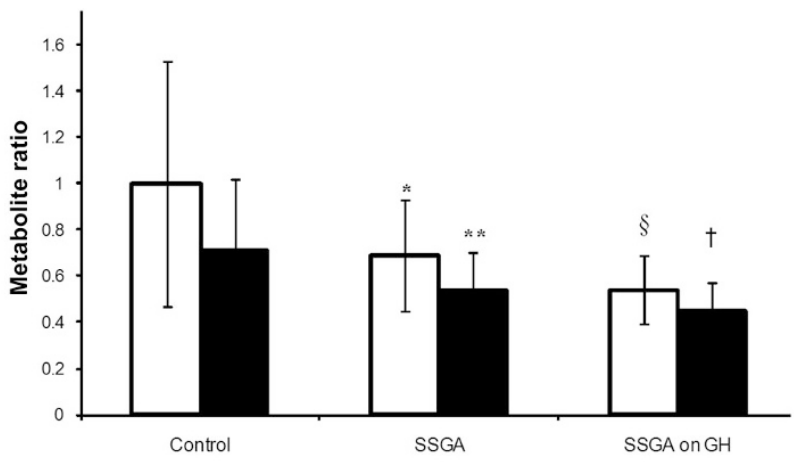

Figure 1. Basal urinary $11 \beta$-HSD-1 activity in SSGA and control children, as calculated from the product/substrate ratios (THF + allo THF)/THE ( $\square$ ) and $(\mathrm{THF}+$ allo $\mathrm{THF}+\mathrm{a}-\mathrm{C}+\mathrm{b}-\mathrm{C}) /(\mathrm{THE}+\mathrm{a}-\mathrm{CL}+\mathrm{b}-\mathrm{CL})(\boldsymbol{\square})$. Mean $\pm \mathrm{SD}$, control vs SSGA, ${ }^{*} p=0.034,{ }^{*} p=0.044$. Basal $v s$. hGH-treated calculated urinary $11 \beta$-HSD- 1 activity in SSGA. Mean $\pm \mathrm{SD}, \S p=0.008, \uparrow p=0.014$.

Overnight DEX suppressed $0800 \mathrm{~h}$ endogenous cortisol to mean values of $28 \pm 20$ and $23 \pm 17 \mathrm{nmol} / \mathrm{L}$ in SSGA and control groups, respectively. Cortisol levels after subtracting baseline cortisol are presented in Figure 2. GC-stimulated $11 \beta$-HSD- 1 activity, as reflected by cortisone-generated cortisol, was enhanced in SSGA children versus controls; SSGA children had maximal cortisol generation of $883 \pm 108$ compared with $690 \pm 63 \mathrm{nmol} / \mathrm{L}$ in controls $(p>0.040)$.

Three-month treatment with hGH in SSGA children resulted in height velocity SDS of $3.8 \pm 1.7$, and increased IGF-1 levels from $105 \pm 71$ to $150 \pm 82 \mathrm{ng} / \mathrm{mL}(p<0.02)$. hGH treatment of SSGA children resulted in a reduction of calculated urinary $11 \beta$-HSD-1 activity, expressed as (THF+ allo THF)/THE ratio, from $0.69 \pm 0.24$ to $0.54 \pm 0.15(p>$ $0.008)$; and (THF + allo THF + a-C + b-C)/(THE + a-CL + bCL) from $0.53 \pm 0.16$ to $0.45 \pm 0.12(p>0.014$, Fig. 1$)$. hGH therapy inhibited GC-stimulated $11 \beta$-HSD-1 activity in SSGA and normalized it to $750 \pm 63 \mathrm{nmol} / \mathrm{L}(p<0.05)$, levels that are not statistically different from normal controls (Fig. 2).

In SSGA, but not in control children, GC-stimulated $11 \beta$ HSD-1 activity correlated negatively with both GA $(r=$ $-0.53, p<0.01)$ and birth weight $(r=-0.55, p<0.01$, Fig. 3); activity was higher in children with shorter gestation and lower birth weight. GC-stimulated $11 \beta$-HSD-1 activity did not correlate with age, height SDS, weight SDS, BMI SDS, or Homeostatic Model Assessment for Insulin Resistance (HOMA-IR), and there was no sexual dimorphism. GC-stimulated $11 \beta$-HSD-1 activities did not correlate with the growth response to GH therapy, and urinary calculated $11 \beta$ HSD-1 activity did not correlate with any anthropometric or metabolic parameter. Due to lack of statistical evidence of a relation between body size and $11 \beta$-HSD-1 activity, no adjustment was made for body size in calculations relating to SSGA children.

\section{DISCUSSION}

The pathophysiology of the increased risk for metabolic syndrome in SGA individuals is poorly understood. Nevertheless, this risk has been clinically documented. Several theories 
Table 2. Urinary $11 \beta-H S D-2$ and $5 \alpha$ reductase activities of controls vs SSGA before and on GH (mean $\pm S D)$

\begin{tabular}{lcccc}
\hline & SSGA & Controls & $p$ & SSGA on GH \\
\hline $5 \alpha$-reductase activity & & & & \\
An/Et & $0.9 \pm 0.4$ & $1.1 \pm 0.6$ & 0.12 & $0.9 \pm 0.5$ \\
11-OH-An/11-OH-Et & $2.6 \pm 3.3$ & $1.1 \pm 0.3$ & 0.12 & $1.9 \pm 1.4$ \\
allo THB/THB & $2.7 \pm 1.9$ & $3.7 \pm 2.1$ & 0.87 & $3.0 \pm 2.0$ \\
allo THF /THF & $0.8 \pm 0.3$ & $0.9 \pm 0.4$ & 0.53 & $0.7 \pm 0.3$ \\
11ß-HSD-2 activity & & & 0.99 \\
THE/(THF + allo THF) & $1.58 \pm 0.53$ & $1.36 \pm 0.62$ & 0.31 & 0.85 \\
(a-CL + b-CL)/(a-C + b-C) & $4.6 \pm 1.7$ & $5.5 \pm 2.58$ & 0.23 & 0.1 \\
\hline
\end{tabular}

An, androsterone; Et, etiocholanalone; 11-OH-An, 11-hydroxy-androsterone; 11-OH-Et, 11-hydroxyl-etiocholanalone; allo THB, 5 a tetrahydrocorticosterone.

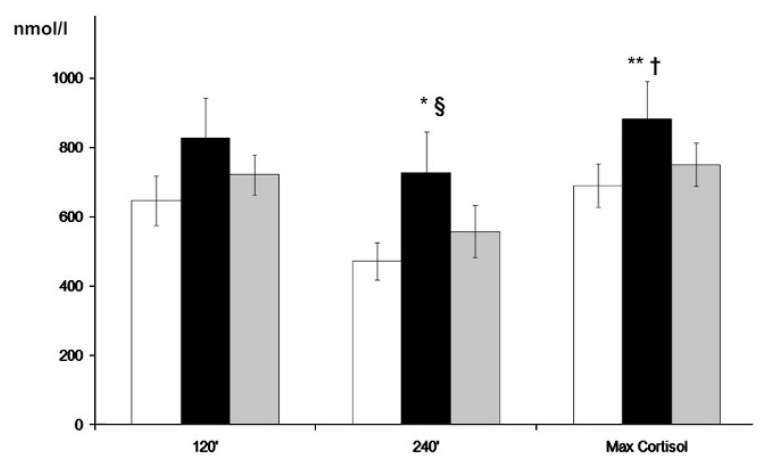

Figure 2. GC-stimulated cortisol generation in SSGA ( $\mathbf{\square})$ and control children ( $\square$ ). Mean \pm SEM, control vs SSGA, ${ }^{*} p<\mathbf{0 . 0 1 2}$ (at $\mathbf{2 4 0}{ }^{\prime}$ ), $* * p<0.04$ (maximum cortisol). GH effect on GC-stimulated $11 \beta$-HSD-1 activity in SSGA $(\square)$ compared with SSGA before treatment $(\square)$. Mean \pm SEM, $\$ p<$ 0.04 (at 240'), $\uparrow p<0.05$ (maximum cortisol). Baseline cortisol was subtracted from each data point.

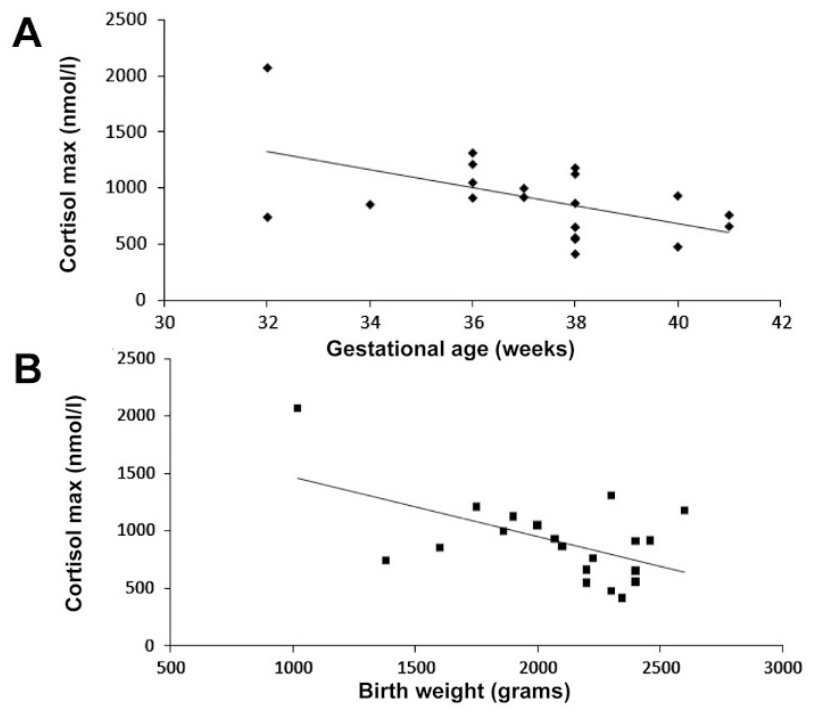

Figure 3. (A) GC-stimulated $11 \beta$-HSD-1 activity as a function of GA. $r=$ $-0.53, p=0.01$. (B) GC-stimulated $11 \beta$-HSD-1 activity as a function of birth weight. $r=-0.55, p=0.01$.

have been proposed to explain the connection between fetal growth and metabolic morbidity (36-38). One theory suggests that increased fetal exposure to cortisol might program the fetus for later hypertension and metabolic disease $(39,40)$. In pregnant rats, dietary restriction has been shown to induce hypomethylation of GC receptor genes in the liver of the offspring (41).
Results of this study show basal activity of $11 \beta$-HSD- 1 to be lower in SSGA children than in controls, while GCstimulated activity, measured as cortisol generation from cortisone, was higher. In SSGA children, 3 mo of GH treatment down-regulated and normalized $11 \beta$-HSD-1 activity. This difference may be due to GC induction of $11 \beta$-HSD1 at the transcriptional level (42).

There are several limitations, which were unavoidable in the design of this study. DEX, which is known to up-regulate $11 \beta$-HSD-1 (43), is an essential component in the in vivo cortisol generation test and is required to suppress endogenous cortisol production. On the other hand, DEX suppression is not required for enzyme activity assessment by urinary metabolites. We therefore present the two aspects separately, showing GCMS-based calculation of enzyme activity in the basal state and GC-stimulated cortisol generation.

The urinary metabolite ratios $(\mathrm{Fm} / \mathrm{Em}-\mathrm{Cortisol}$ metabolites/Cortisone metabolites) reflect the combined activity of $11 \beta$-HSD-1, $11 \beta$-HSD2, and the relative activity of the A-ring reductase. Urinary $11 \beta$-HSD-2 and $5 \alpha$ reductase activities were comparable in SSGA and controls, and therefore we used urine metabolite ratio as a measure of global $11 \beta$-HSD-1 activity.

The contribution of the HPA axis to growth and morbidity in SGA has been addressed extensively in the literature (21$24,44,45)$. For one, SSGA children have demonstrated less suppression by DEX, a finding that might be related to reports of their having a higher $0800 \mathrm{~h}$ cortisol level $(21,45)$.

This study concurs with data suggesting dysregulation of GCs in SGA (19), a phenomenon that may contribute to the pathogenesis of metabolic morbidity (46) and that has been demonstrated even in the absence of overt obesity $(47,48)$. In obese subjects, the intra-adipose in vitro $11 \beta$-HSD-1 was found to be increased (49). Its in vivo activity has been reported to be increased $(50,51)$, decreased $(33,52)$, or unchanged (53).

A recent study demonstrates that basal in vivo $11 \beta$-HSD-1 activity in adipose tissue of young adults born SGA was comparable with controls, while stimulated activity was decreased (54). 11 $\beta$-HSD-1 gene expression was associated with body fat but not with birth weight. We studied Fm/Em urinary ratio that reflects global activity of the $11 \beta$-HSD-1, while the liver contributes most of this activity, and it was found to be decreased in SSGA.

As expected, the mean BMI of SSGA children was lower than that of age-matched control subjects. This lower BMI 
may explain the lower basal $11 \beta$-HSD- 1 activity, but not the higher GC-stimulated activity. Enhanced generation of cortisol from cortisone after GC stimulation may explain the enhanced reactivity to stress in SGA individuals and may contribute to their metabolic morbidity in adult life $(20,55)$.

We found GC-stimulated $11 \beta$-HSD- 1 activity to correlate inversely with birth weight (the degree of SGA) and GA (prematurity). Enhanced GC-stimulated $11 \beta$-HSD-1 activity in children with shorter gestation and lower birth weight SDS is in agreement with previous reports of cortisol levels in SGA $(21,22,56)$. However, this finding did not correlate with age, indicating that the process is not progressive, but rather programmed from birth. Neither did it correlate with height SDS, indicating that it is not a function of children's short stature. No correlation was found with weight SDS or BMI SDS, indicating that GC-stimulated enzyme activity is not a response to thin body composition. Of note is that correlation to BMI is only in the low to normal range, because no obese children were included in our study. GC-stimulated $11 \beta$ HSD-1 activity did not correlate with HOMA-IR, indicating that it is not secondary to the known insulin resistance of SGA children.

This is in agreement with the GH-suppressing effect on $11 \beta$-HSD-1, which has been documented in vitro and in vivo $(28-31)$. We are not able to assess whether this enzyme modulation has any effect on the growth response to $\mathrm{GH}$ therapy. Nevertheless, there was no correlation between basal or GC-stimulated $11 \beta$-HSD-1 activity and the child's response to GH. Our study was designed for a 3-mo period, and as such evaluates only short-term metabolic effects of $\mathrm{GH}$, and no conclusion can be drawn on whether GH effect is sustained.

In conclusion, we demonstrated that SSGA programs a biphasic $11 \beta$-HSD-1 response. We speculate that enhanced GC-stimulated $11 \beta$-HSD-1 activity may be a contributing factor in SSGA metabolic morbidity and suggest another indication for GH therapy in SSGA: normalization of $11 \beta$ HSD-1 activity.

Acknowledgments. The authors are indebted to Novonordisk Israel for compassionate provision of Norditropin Simplexx.

\section{REFERENCES}

1. Hokken-Koelega AC, De Ridder MA, Lemmen RJ, Den Hartog H, De Muinck Keizer-Schrama SM, Drop SL 1995 Children born small for gestational age: do they catch up? Pediatr Res 38:267-271

2. Karlberg J, Albertsson-Wikland K 1995 Growth in full-term small-for-gestationalage infants: from birth to final height. Pediatr Res 38:733-739

3. Clayton PE, Cianfarani S, Czernichow P, Johannsson G, Rapaport R, Rogol A 2007 Management of the child born small for gestational age through to adulthood: a consensus statement of the International Societies of Pediatric Endocrinology and the Growth Hormone Research Society. J Clin Endocrinol Metab 92:804-810

4. Dahlgren J, Wikland KA 2005 Final height in short children born small for gestational age treated with growth hormone. Pediatr Res 57:216-222

5. Van Pareren Y, Mulder P, Houdijk M, Jansen M, Reeser M, Hokken-Koelega A 2003 Adult height after long-term, continuous growth hormone $(\mathrm{GH})$ treatment in short children born small for gestational age: results of a randomized, double-blind, dose-response GH trial. J Clin Endocrinol Metab 88:3584-3590

6. Barker DJ, Bull AR, Osmond C, Simmonds SJ 1990 Fetal and placental size and risk of hypertension in adult life. BMJ 301:259-262

7. Barker DJ, Winter PD, Osmond C, Margetts B, Simmonds SJ 1989 Weight in infancy and death from ischaemic heart disease. Lancet 2:577-580

8. Eriksson JG, Forsen T, Tuomilehto J, Winter PD, Osmond C, Barker DJ 1999 Catch-up growth in childhood and death from coronary heart disease: longitudinal study. BMJ 318:427-431
9. Mericq V, Ong KK, Bazaes R, Pena V, Avila A, Salazar T, Soto N, Iniguez G, Dunger DB 2005 Longitudinal changes in insulin sensitivity and secretion from birth to age three years in small- and appropriate-for-gestational-age children. Diabetologia 48:2609-2614

10. Saenger P, Czernichow P, Hughes I, Reiter EO 2007 Small for gestational age: short stature and beyond. Endocr Rev 28:219-251

11. Fagerberg B, Bondjers L, Nilsson P 2004 Low birth weight in combination with catch-up growth predicts the occurrence of the metabolic syndrome in men at late middle age: the Atherosclerosis and Insulin Resistance study. J Intern Med 256:254 259

12. Jaquet D, Deghmoun S, Chevenne D, Collin D, Czernichow P, Levy-Marchal C 2005 Dynamic change in adiposity from fetal to postnatal life is involved in the metabolic syndrome associated with reduced fetal growth. Diabetologia 48:849-855

13. Veening MA, Van Weissenbruch MM, Delemarre-Van De Waal HA 2002 Glucose tolerance, insulin sensitivity, and insulin secretion in children born small for gestational age. J Clin Endocrinol Metab 87:4657-4661

14. Tenhola S, Martikainen A, Rahiala E, Herrgard E, Halonen P, Voutilainen R 2000 Serum lipid concentrations and growth characteristics in 12-year-old children born small for gestational age. Pediatr Res 48:623-628

15. Hokken-Koelega AC, De Waal WJ, Sas TC, Van Pareren Y, Arends NJ 2004 Small for gestational age (SGA): endocrine and metabolic consequences and effects of growth hormone treatment. J Pediatr Endocrinol Metab 17:463-469

16. Arends NJ, Boonstra VH, Duivenvoorden HJ, Hofman PL, Cutfield WS, HokkenKoelega AC 2005 Reduced insulin sensitivity and the presence of cardiovascular risk factors in short prepubertal children born small for gestational age (SGA). Clin Endocrinol (Oxf) 62:44-50

17. Cianfarani S, Ladaki C, Geremia C 2006 Hormonal regulation of postnatal growth in children born small for gestational age. Horm Res 65:70-74

18. Clark PM, Hindmarsh PC, Shiell AW, Law CM, Honour JW, Barker DJ 1996 Size at birth and adrenocortical function in childhood. Clin Endocrinol (Oxf) 45:721-726

19. Murphy VE, Smith R, Giles WB, Clifton VL 2006 Endocrine regulation of human fetal growth: the role of the mother, placenta, and fetus. Endocr Rev 27:141-169

20. Tenhola S, Martikainen A, Rahiala E, Parviainen M, Halonen P, Voutilainen R 2002 Increased adrenocortical and adrenomedullary hormonal activity in 12-year-old children born small for gestational age. J Pediatr 141:477-482

21. Phillips DI, Walker BR, Reynolds RM, Flanagan DE, Wood PJ, Osmond C, Barker DJ, Whorwood CB 2000 Low birth weight predicts elevated plasma cortisol concentrations in adults from 3 populations. Hypertension 35:1301-1306

22. Cianfarani S, Geremia C, Scott CD, Germani D 2002 Growth, IGF system, and cortisol in children with intrauterine growth retardation: is catch-up growth affected by reprogramming of the hypothalamic-pituitary-adrenal axis? Pediatr Res 51:94-99

23. Economides DL, Nicolaides KH, Linton EA, Perry LA, Chard T 1988 Plasma cortisol and adrenocorticotropin in appropriate and small for gestational age fetuses. Fetal Ther 3:158-164

24. Tenhola S, Turpeinen U, Halonen P, Hamalainen E, Voutilainen R 2005 Association of serum lipid concentrations, insulin resistance index and catch-up growth with serum cortisol/cortisone ratio by liquid chromatography tandem mass spectrometry in children born small for gestational age. Pediatr Res 58:467-471

25. Cianfarani S, Germani D, Rossi L, Argiro G, Boemi S, Lemon M, Holly JM, Branca F 1998 IGF-I and IGF-binding protein-1 are related to cortisol in human cord blood. Eur J Endocrinol 138:524-529

26. Fruchter O, Zoumakis E, Alesci S, De Martino M, Chrousos G, Hochberg Z 2006 Intracrine modulation of gene expression by intracellular generation of active glucocorticoids. Steroids 71:1001-1006

27. Friedberg M, Zoumakis E, Hiroi N, Bader T, Chrousos GP, Hochberg Z 2003 Modulation of 11 beta-hydroxysteroid dehydrogenase type 1 in mature human subcutaneous adipocytes by hypothalamic messengers. J Clin Endocrinol Metab 88:385-393

28. Agha A, Monson JP 2007 Modulation of glucocorticoid metabolism by the growth hormone - IGF-1 axis. Clin Endocrinol (Oxf) 66:459-465

29. Gelding SV, Taylor NF, Wood PJ, Noonan K, Weaver JU, Wood DF, Monson JP 1998 The effect of growth hormone replacement therapy on cortisol-cortisone interconversion in hypopituitary adults: evidence for growth hormone modulation of extrarenal 11 beta-hydroxysteroid dehydrogenase activity. Clin Endocrinol (Oxf) 48:153-162

30. Moore JS, Monson JP, Kaltsas G, Putignano P, Wood PJ, Sheppard MC, Besser GM, Taylor NF, Stewart PM 1999 Modulation of 11beta-hydroxysteroid dehydrogenase isozymes by growth hormone and insulin-like growth factor: in vivo and in vitro studies. J Clin Endocrinol Metab 84:4172-4177

31. Paulsen SK, Pedersen SB, Jorgensen JO, Fisker S, Christiansen JS, Flyvbjerg A, Richelsen B 2006 Growth hormone (GH) substitution in GH-deficient patients inhibits 11beta-hydroxysteroid dehydrogenase type 1 messenger ribonucleic acid expression in adipose tissue. J Clin Endocrinol Metab 91:1093-1098

32. Tiosano D, Knopf C, Koren I, Levanon N, Hartmann MF, Hochberg Z, Wudy SA 2008 Metabolic evidence for impaired 17alpha-hydroxylase activity in a kindred bearing the E305G mutation for isolate 17,20-lyase activity. Eur J Endocrinol 158:385-392

33. Stewart PM, Boulton A, Kumar S, Clark PM, Shackleton CH 1999 Cortisol metabolism in human obesity: impaired cortisone $\rightarrow$ cortisol conversion in subjects with central adiposity. J Clin Endocrinol Metab 84:1022-1027

34. Stewart PM, Corrie JE, Shackleton CH, Edwards CR 1988 Syndrome of apparent mineralocorticoid excess. A defect in the cortisol-cortisone shuttle. J Clin Invest 82:340-349

35. Palermo M, Shackleton CH, Mantero F, Stewart PM 1996 Urinary free cortisone and the assessment of 11 beta-hydroxysteroid dehydrogenase activity in man. Clin Endocrinol (Oxf) 45:605-611 
36. Neel JV 1962 Diabetes mellitus: a "thrifty" genotype rendered detrimental by "progress"? Am J Hum Genet 14:353-362

37. Hales CN, Barker DJ 1992 Type 2 (non-insulin-dependent) diabetes mellitus: the thrifty phenotype hypothesis. Diabetologia 35:595-601

38. Barker DJ, Hales CN, Fall CH, Osmond C, Phipps K, Clark PM 1993 Type 2 (non-insulin-dependent) diabetes mellitus, hypertension and hyperlipidaemia (syndrome X): relation to reduced fetal growth. Diabetologia 36:62-67

39. Jansson T, Powell TL 2007 Role of the placenta in fetal programming: underlying mechanisms and potential interventional approaches. Clin Sci (Lond) 113:1-13

40. Dodic M, Moritz K, Wintour EM 2003 Prenatal exposure to glucocorticoids and adult disease. Arch Physiol Biochem 111:61-69

41. Simmons RA 2007 Developmental origins of diabetes: the role of epigenetic mechanisms. Curr Opin Endocrinol Diabetes Obes 14:13-16

42. Sai S, Esteves CL, Kelly V, Michailidou Z, Anderson K, Coll AP, Nakagawa Y, Ohzeki T, Seckl JR, Chapman KE 2008 Glucocorticoid regulation of the promoter of 11 beta-hydroxysteroid dehydrogenase type 1 is indirect and requires CCAAT/ enhancer-binding protein-beta. Mol Endocrinol 22:2049-2060

43. Jamieson PM, Chapman KE, Seckl JR 1999 Tissue- and temporal-specific regulation of 11 beta-hydroxysteroid dehydrogenase type 1 by glucocorticoids in vivo. J Steroid Biochem Mol Biol 68:245-250

44. Ward AM, Syddall HE, Wood PJ, Chrousos GP, Phillips DI 2004 Fetal programming of the hypothalamic-pituitary-adrenal (HPA) axis: low birth weight and central HPA regulation. J Clin Endocrinol Metab 89:1227-1233

45. Dahlgren J, Boguszewski M, Rosberg S, Albertsson-Wikland K 1998 Adrenal steroid hormones in short children born small for gestational age. Clin Endocrinol (Oxf) 49:353-361

46. Putignano P, Pecori Giraldi F, Cavagnini F 2004 Tissue-specific dysregulation of 11beta-hydroxysteroid dehydrogenase type 1 and pathogenesis of the metabolic syndrome. J Endocrinol Invest 27:969-974

47. Paterson JM, Morton NM, Fievet C, Kenyon CJ, Holmes MC, Staels B, Seckl JR, Mullins JJ 2004 Metabolic syndrome without obesity: Hepatic overexpression of 11beta-hydroxysteroid dehydrogenase type 1 in transgenic mice. Proc Natl Acad Sci U S A 101:7088-7093

48. Nair S, Lee YH, Lindsay RS, Walker BR, Tataranni PA, Bogardus C, Baier LJ, Permana PA 2004 11beta-Hydroxysteroid dehydrogenase Type 1: genetic polymorphisms are associated with type 2 diabetes in Pima Indians independently of obesity and expression in adipocyte and muscle. Diabetologia 47:1088-1095

49. Bujalska IJ, Kumar S, Stewart PM 1997 Does central obesity reflect "Cushing's disease of the omentum"? Lancet 349:1210-1213

50. Andrew R, Phillips DI, Walker BR 1998 Obesity and gender influence cortisol secretion and metabolism in man. J Clin Endocrinol Metab 83:1806-1809

51. Tiosano D, Eisentein I, Militianu D, Chrousos GP, Hochberg Z 200311 betaHydroxysteroid dehydrogenase activity in hypothalamic obesity. J Clin Endocrinol Metab 88:379-384

52. Valsamakis G, Anwar A, Tomlinson JW, Shackleton CH, McTernan PG, Chetty R, Wood PJ, Banerjee AK, Holder G, Barnett AH, Stewart PM, Kumar S 2004 11beta-hydroxysteroid dehydrogenase type 1 activity in lean and obese males with type 2 diabetes mellitus. J Clin Endocrinol Metab 89:4755-4761

53. Fraser R, Ingram MC, Anderson NH, Morrison C, Davies E, Connell JM 1999 Cortisol effects on body mass, blood pressure, and cholesterol in the general population. Hypertension 33:1364-1368

54. Meas T, Carreira E, Wang Y, Rauh M, Poitou C, Clement K, Dotsch J, LevyMarchal C 2010 11beta-hydroxysteroid dehydrogenase type 1 of the subcutaneous adipose tissue is dysregulated but not associated with metabolic disorders in adults born small for gestational age. J Clin Endocrinol Metab 95:3949-3954

55. Dalla Pozza RD, Bechtold S, Putzker S, Bonfig W, Netz H, Schwarz HP 2006 Young adults born small for gestational age: is reduced baroreceptor sensitivity a risk factor for hypertension? Clin Cardiol 29:215-218

56. Buske-Kirschbaum A, Krieger S, Wilkes C, Rauh W, Weiss S, Hellhammer DH 2007 Hypothalamic-pituitary-adrenal axis function and the cellular immune response in former preterm children. J Clin Endocrinol Metab 92:3429-3435 